\title{
Epidemiological Profile of Male Infertility in Two Hospitals of Douala: A Cross-Sectional Study in a Sub-Saharan Africa Setting
}

\author{
Frantz Guy Epoupa Ngalle ${ }^{1,2, *}$, Kelly Donfack², Edouard Herve Moby Mpah ${ }^{2,3}$, \\ Sylvain Raoul Simeni Njonnou ${ }^{4}$, Charlotte Tchente Nguefack ${ }^{2,5}$ \\ ${ }^{1}$ Department of Surgery, Douala General Hospital, Douala, Cameroon \\ ${ }^{2}$ Department of Surgery, Faculty of Medicine and Pharmaceutical Sciences, University of Douala, Douala, Cameroon \\ ${ }^{3}$ Nkongsamba Regional Hospital, Nkongsamba, Cameroon \\ ${ }^{4}$ Department of Internal Medicine and Specialties, Faculty of Medicine and Pharmaceutical Sciences, University of Dschang, Dschang, \\ Cameroon \\ ${ }^{5}$ Department of Gynaecology, Douala General Hospital, Douala, Cameroon
}

Email address :

frantzepoupa@gmail.com (F. G. E. Ngalle)

${ }^{*}$ Corresponding author

\section{To cite this article:}

Frantz Guy Epoupa Ngalle, Kelly Donfack, Edouard Herve Moby Mpah, Sylvain Raoul Simeni Njonnou, Charlotte Tchente Nguefack. Epidemiological Profile of Male Infertility in Two Hospitals of Douala: A Cross-Sectional Study in a Sub-Saharan Africa Setting. International Journal of Clinical Urology. Vol. 4, No. 2, 2020, pp. 85-91. doi: 10.11648/j.ijcu.20200402.22

Received: October 17, 2020; Accepted: November 2, 2020; Published: November 11, 2020

\begin{abstract}
Background: Male infertility is defined as a lack of pregnancy for a couple after 12 months of regular and normal sexual intercourse without contraception with the cause being clearly from the male origin. Contrary to popular belief, the prevalence of male infertility is similar to that of female infertility and sometimes even higher. However, data on the subject in Cameron are scarce and nonexistent in the city of Douala. This motivated the realization of this study in two centers in the city of Douala. The objective was to describe the epidemiological profile of male infertility. Methods: We conducted a crosssectional study among patients who consulted for infertility in two hospital centers in Douala from January 2014 to October 2019. A consecutive sample of all eligible cases was considered for this study. Data were analyzed using Statistical Package for Social Sciences (SPSS Inc, Chicago, Illinois, USA) V. 20.0 and EPI-INFO V. 3.5 software. Analyzed variables included sociodemographic data (age, marital status, educational level, profession, region, alcohol, smoking habit and mean infertility duration) and other causes of infertility (obesity, history of testes infection, STI, testes traumatism, varicocele or varicocele surgery, herniorrhaphy, genetic or malformative disease). Results: We included 137 patients' records. The frequency of male infertility for patients consulting in urology was $5.6 \%$. Their average age was $35.4 \pm 7.4$ years. The average number of sexual intercourses per week was $2.7 \pm 0.97$. Those patients were mainly from an intellectual profession $(40.2 \%)$, married $(71.5 \%)$ with a higher education level (67.2\%). Almost $60 \%$ of the studied population had alcohol consumption. Primary infertility accounted for $65.7 \%$ of the study population and the average duration of infertility was $5.9 \pm 5.3$ years. The main factors for infertility were respectively history of sexually transmitted infections (STI) in $59(43.1 \%)$ and childhood mumps in $42(32.7 \%)$ cases. Furthermore, herniorrhaphy (16.1\%) and varicocelectomy (10.9\%) were the most representative surgical background. Conclusion: Male infertility is not uncommon in urological consultation with primary infertility been more frequent. Risk factors of infertility in our setting included a history of STI, mumps, and surgery.
\end{abstract}

Keywords: Epidemiology, Male Infertility, Sub-Saharan Africa Setting 


\section{Introduction}

The World Health Organization (WHO) defines infertility as the absence of pregnancy after more than twelve months of regular and normal sexual intercourse without contraception [1]. It can be female or male. Infertility is said to be male when the anomaly is due to man. It can be primary or secondary, depending on whether he has already fertilized a woman or not [2]. Nowadays, it represents a real public health problem because of its frequency, the impact on the quality of life, and the difficulties inherent in its diagnosis and its cost burden. Currently, in increasingly industrialized societies, the absence of a desired pregnancy is accompanied by a profound psychological and emotional impact on the couple [3]. The distribution of couples' infertility is variable around the world. Thus, it is $25 \%$ in China according to Zhou et $a l$. in $2017,6 \%$ in the United States according to Chandra et $a l ., 10-15 \%$ in England according to Oakley et al. [4-6].

Concerning male infertility, Agarwal et al., in a systematic review, found higher rates of male infertility in Central and Eastern Europe (8-12\%), Australia (8-9\%) and Europe (7.5\%) than North America (4.5-6\%) and Sub-Saharan Africa (2.5$4.8 \%$ ) [7]. Recent studies in India found a frequency of $20.4 \%$ of pure male factor in infertile couple, associated with several factors such as a history of varicocele surgery, STI, alcohol consumption, diabetes, small size testis and tobacco [8, 9]. One-third of these patients had erectile dysfunction while half had azoospermia or oligospermia [8]. In China, Cong et al. found an increased risk of infertility in those engaged in occupations with the high-temperature working environment [10]; while tobacco (29\%) and history of varicocele surgery $(22 \%)$ were the main risk factors for male infertility in Iran [11]. Furthermore, azoospermia and oligospermia represented $4 \%$ and $23 \%$ [10]. In contrast, Aziz et al. in the United States of America (USA) found no association between tobacco, alcohol, occupation and the etiologies of male infertility. Genetic predispositions were highlighted as the major factor responsible for male infertility in this study [12].

There are few data on male infertility in Africa. Although lower compared to the other parts of the world, infertility rates vary in Sub-Saharan Africa (SSA) [7]. In Nigeria, Olatunji and Sule-Odu found $14.8 \%$ of infertile couples with $30 \%$ due to pure male infertility [13]. Gyasi-Sarpong et al., in Ghana, identified respectively 58.2 and $41.8 \%$ of primary and secondary infertility in male patients; with varicoceles and small volumes testes among the main risk factors [14]. In Cameroon, two studies were performed on infertility. Nana et al. found $11.5 \%$ of pure male infertility in our environment, with asthenospermia and varicocele been the main etiologies [15]. Voundi Voundi et al. found that the main risk factors associated with semen abnormalities were varicocele, congenital anorchia and mumps history [16].

This cross-sectional study aimed at characterizing the epidemiological profile and the risk factors for male infertility in two main hospital centers in Douala, SubSaharan Africa.

\section{Methods}

Study design and setting: This cross-sectional study was carried out in two therapeutic centers for infertility management in Douala (Douala General Hospital and the Urological Medico-surgical Centre of Douala). Douala General Hospital (DGH) is a tertiary hospital in Douala, the largest of Cameroon (SSA), while the Urological Medicosurgical Centre of Douala (UMSCD) is a private medical institution with a high technology platform.

Study population: We retrospectively reviewed files of male patients seen in outpatient consultation consulting for infertility from January 2014 to October 2019 via clinical records. Patients followed-up, but not seen at outpatient's consultation were contacted by telephone and invited to participate in the study.

Variables and Measurements: We included all files of consenting patients that have performed a seminogram. Patient files were reviewed and patients were contacted to provide some specific information. The files of patients who refused to participate and the incomplete files were excluded. Data on sociodemographic characteristics (age in years, gender, profession, alcohol intake, tobacco consumption) and other risk factors for male infertility (obesity, history of testes infection, STI, testes traumatism, varicocele or varicocele surgery, herniorrhaphy, genetic or malformative disease). Excessive alcohol consumption was considered for a consumption $>40 \mathrm{~g} /$ day for men or more than 10 local beers per week.

Definition of operational terms:

Infertility was defined as the absence of pregnancy after more than twelve months of regular and normal sexual intercourse without contraception. Primary male infertility characterizes the situation when a man has never fertilized a woman, (regardless of the course of the pregnancy). Secondary male infertility is used when a man has fertilized a woman, regardless of whether she is the current partner, and regardless of the course of the pregnancy [1].

Varicocele is defined by the presence of varicose dilation of the veins in the anterior pampiniform plexus of the testicle [17].

Intermediate work refers to a professional category in which people have an intermediate position between managers and agents of execution [18].

Intellectual work refers to a professional category that includes professors and scientific professions who directly apply very in-depth knowledge in the fields of the exact or human sciences to activities of general interest in research, teaching or health, as well as managers, engineers, professionals in the arts and entertainment [18].

Sample size and Statistical analysis: A consecutive sample of all eligible cases was considered for this study. Data were analyzed using Statistical Package for Social Sciences (SPSS Inc, Chicago, Illinois, USA) V. 20.0 and EPI-INFO V. 3.5 software. We have presented discrete variables as counts and percentages, and continuous variables as mean (standard deviation). 


\section{Results}

Participants: A total of 137 (out of 417 identified cases) cases of male infertility were included during the study period, while 7.446 consultations were done in both centers within this period. Male infertility represents $5.6 \%$ of all urological consultations. Figure 1 presents the patient flow chart.

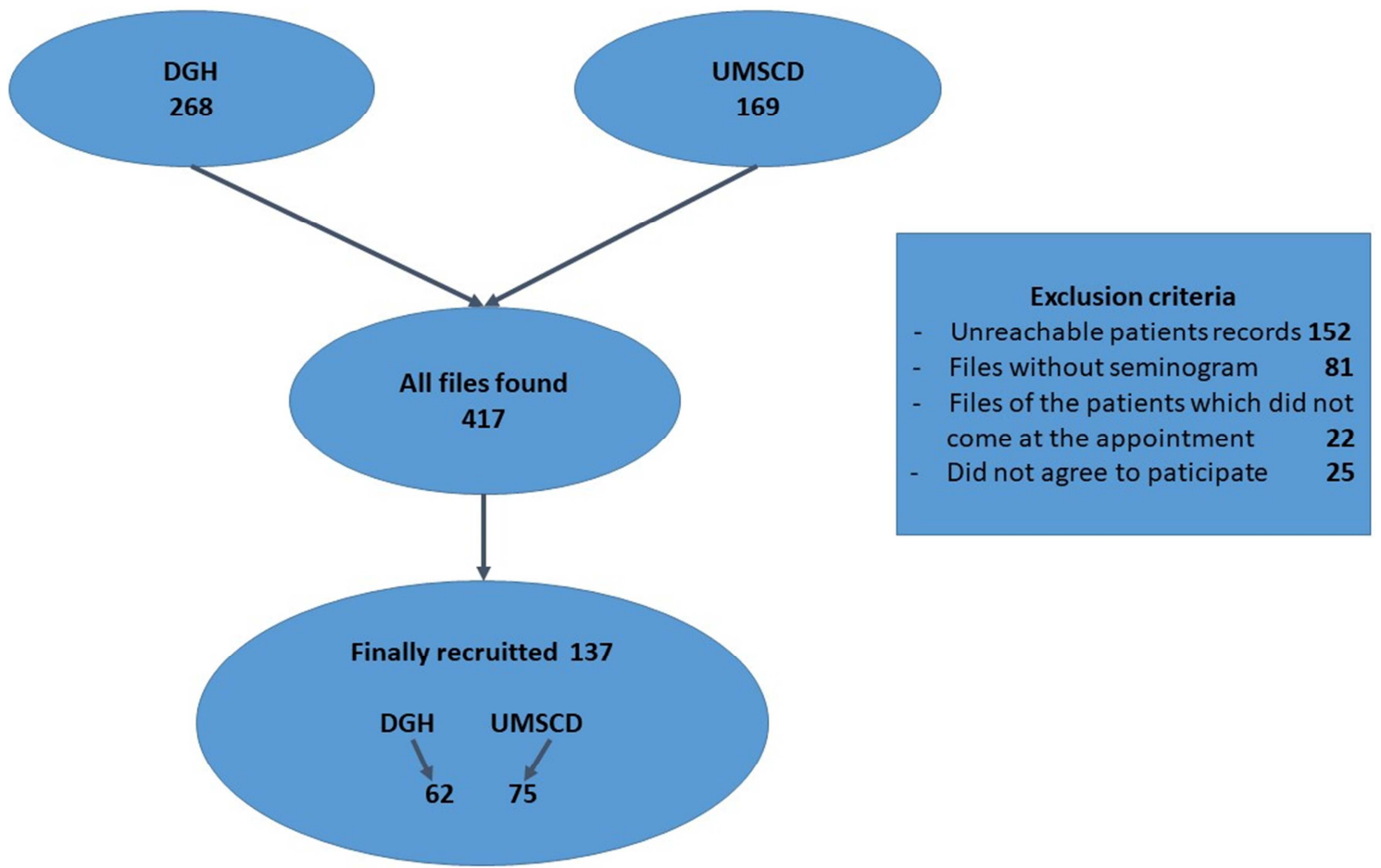

Figure 1. Patient flow chart.

The mean age was $35.4 \pm 7.4$ years. The $30-34$ years age group were the most frequent with $52(38 \%)$ patients (Figure 2). People with an intellectual occupation were the most important professional group with 65 (47.4\%) patients. Almost three over four patients were married (71\%). Most of them $(67 \%)$ had a higher education level. Secondary infertility was the most common $(65.7 \%)$. Mean infertility duration was $5.9 \pm 5.3$ years. Most of the patients $(55.5 \%)$ had an infertility duration between two and five years. Table 1 shows the general characteristics of this population.

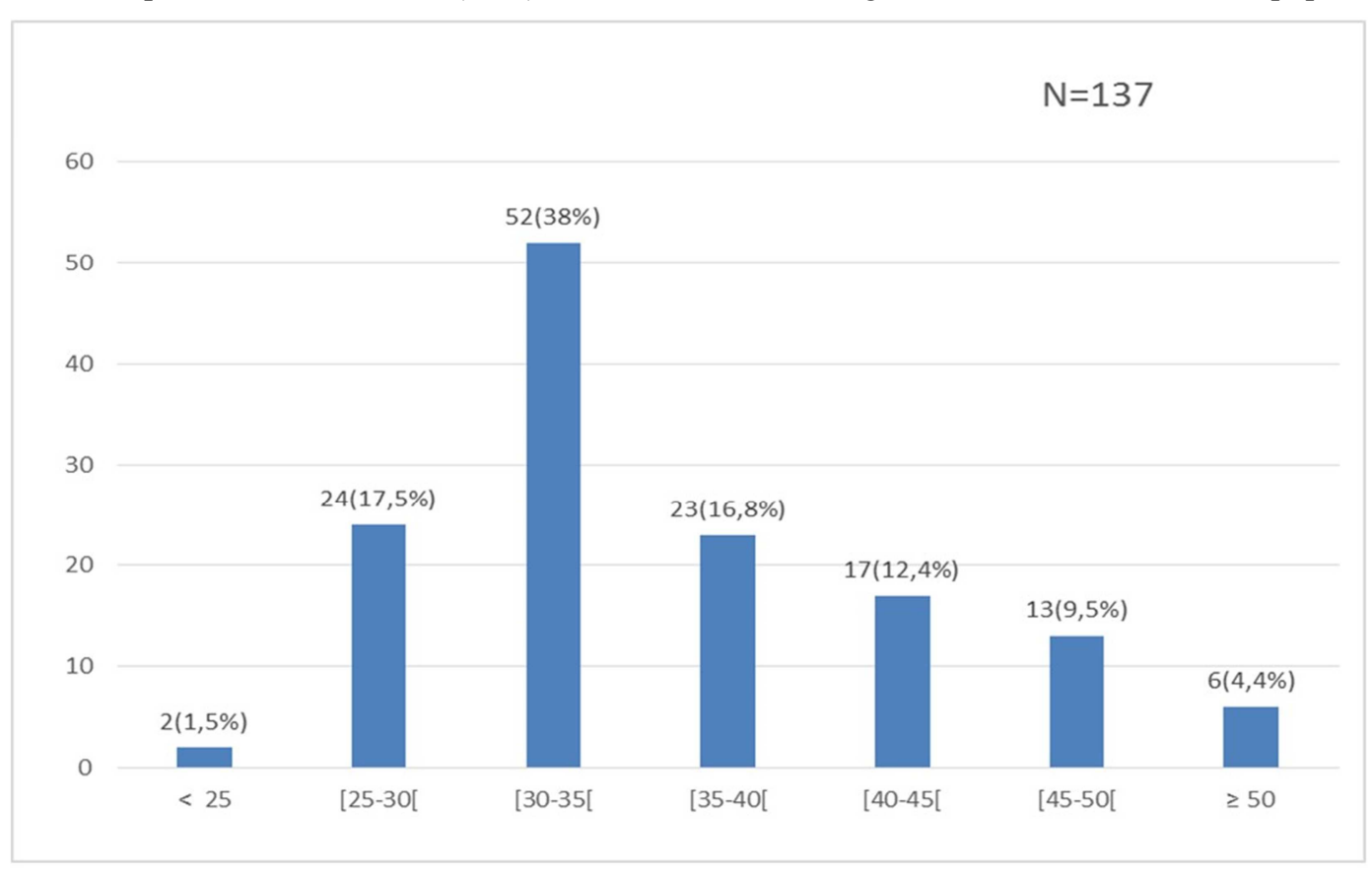

Figure 2. Patient classification by age group. 
Table 1. Population characteristics.

\begin{tabular}{ll}
\hline Variables & Frequency (\%) \\
\hline Occupation & $4(2.9)$ \\
Farmers & $28(20.4)$ \\
Traders & $16(11.7)$ \\
Employees & $5(3.6)$ \\
Students & $14(10.2)$ \\
Workers & $65(47.4)$ \\
Intellectual work & $5(3.6)$ \\
Intermediate work & \\
Marital status & $98(71.5)$ \\
Married & $38(27.8)$ \\
Single & $1(0.7)$ \\
Divorced & \\
Educational level & $18(13.1)$ \\
Primary school & $27(19.7)$ \\
Secondary school & $92(67.2)$ \\
Higher level & \\
Infertility classification & $90(65.7)$ \\
Primary infertility & $47(34.3)$ \\
Secondary infertility & \\
Infertility duration & $27(19.7)$ \\
1 year & $76(55.5)$ \\
2-5 years & $21(15.3)$ \\
6-10 years & $8(5.8)$ \\
11-15 years & $5(3.6)$ \\
16-20 years &
\end{tabular}

STI (43.1\%), mumps history (30.7\%) and herniorrhaphy $(16.1 \%)$ were the main factors in our study population. A varicocele surgery was found in $15(10.9 \%)$ patients while cryptorchidism was found in $11(8.0 \%)$ patients. Alcohol consumption was found in $80(58.4 \%)$ patients and $11(8.0 \%)$ were current smokers. Tables 2 and 3 present medical and surgical risk factors among our study population.

Table 2. Medical factors for male infertility.

\begin{tabular}{ll}
\hline Variables & Frequency (\%) \\
\hline STI & $59(43.1)$ \\
Mumps history & $42(30.7)$ \\
Cryptorchidism & $11(8 / 0)$ \\
Varicocele & $7(5.1)$ \\
Testes traumatism & $7(5.1)$ \\
Hypertension & $7(5.1)$ \\
Hepatitis B or C & $5(3.6)$ \\
Orchitis/epididymitis & $5(3.6)$ \\
Diabetes & $3(2.2)$ \\
Chemotherapy for any cancer & $1(0.7)$ \\
Sickle cell disease & $1(0.7)$ \\
Genetic disease & $2(1.4)$ \\
Klinefelter & $1(0.7)$ \\
\hline
\end{tabular}

Table 3. Surgical factors for male infertility.

\begin{tabular}{ll}
\hline Surgical history & Frequency (\%) \\
\hline Herniorrhaphy & $22(16.1)$ \\
Other surgery (non-urological) & $16(11.7)$ \\
Varicocele surgery & $15(10.9)$ \\
Orchidopexy & $3(2.2)$ \\
Hydrocele surgery & $2(1.5)$ \\
Testicular torsion & $1(0.7)$ \\
\hline
\end{tabular}

\section{Discussion}

This cross-sectional study aimed to describe the epidemiology of patients consulting for male infertility in two hospital centers in Douala. Epidemiology of male infertility is still poorly known in the Sub-Saharan parts of Africa [13, 14, 19-26]. Few studies, especially on the prevalence and risk factors have been carried out in Cameroon $[15,16]$. Our results show that the patients with male infertility are young, have an intellectual profession and high educational level, suffer mostly from primary infertility. The main medical factors for infertility were STI, childhood mumps in $42(32.7 \%)$ cases. Furthermore, herniorrhaphy $(16.1 \%)$ and varicocelectomy $(10.9 \%)$ were the most representative surgical background.

Male infertility prevalence in urological consult was 5.6\% in Douala. This frequency was higher than the one found in Burkina Faso by Kirakoya et al. (3,6\%) but lower than the $8.2 \%$ found by Bah et al. $[25,26]$. However, this does not seem to reflect the real level of this pathology in both hospitals and society. Increased urbanization with a sedentary lifestyle, STI, obesity, heavy alcohol consumption in SubSaharan Africa should have increased the prevalence of this disease.

The mean age in our study was $35.4 \pm 7.4$ years. This was similar to Sari-Minodier et al. in Marseille (35.8 \pm 7.3 years) and Kirakoya et al. in Burkina Faso $(36.9 \pm 6.8)$ [25, 27]. In contrast, Punab et al. found a mean age of 33 in Estonia [28]. This age difference could be due to cultural influence with early or late wedding and/or to the health facilities access. But, globally, the male age upper 30 years seems to reflect the need of a child in the couple.

Intellectual workers represent $47.4 \%$ of the study population, followed by traders $(20.4 \%)$. This was similar to Kirakoya et al. findings [25]. In contrast, Niang et al. in Senegal found $13.6 \%$ of intellectual workers; Bah et al. in Guinea, found that workers were the main professional group and Sari-Minodier et $a l$. in Marseille found traders as the main professional group [26, 27, 29]. Those results possibly reflect the financial status of those groups in their countries.

Married patients account for $71 \%$ of the study population. This value varies from each country to another one, higher values in Nigeria (90.7\%) and Ghana (98.2\%) [14, 22]. In Mali, $57.2 \%$ of the study population had only one wife, the others were polygamous. This finding sustains the hypothesis men would seek the solution of their infertility in the marriage of a new wife, sometimes supported by their family [30].

A higher educational level was found in $67 \%$ of our patients. This value varies according to geographic area, with $54.7 \%$ in Nigeria and $35 \%$ in Iran $[11,22]$. This result could reflect either a good understanding of the disease or access to health facilities.

Similar to our findings, primary infertility (65.7\%) was the main in most studies. Moussa et al., in Mali, found $57.8 \%$ of primary infertility [20]. Kirakoya et al., so too, found $68.4 \%$ of 
primary infertility in Burkina Faso while Benbella et al. and Aziz et $a l$., respectively in Morrocco and USA found almost $80 \%$ of male infertility $[12,25,31]$. However, few studies in Nigeria, such as Nwajiaku et al. and Olatunji et al., reported secondary infertility predominance $[13,32]$. This can be a clue of STI's high rate in this setting. The mean infertility duration was $5.9 \pm 5.3$ years. This was similar to Benbella et $a l$., Niang et al. and Kirakoya et al. findings [25, 29, 31].

The most frequent etiological factors found in this study were alcohol consumption, STI, mumps history, herniorrhaphy, and varicocele presence. However, some studies, in contrast to proven knowledge, denied the alcohol consumption impact on male infertility [33]. Okonofua et al., so, did not find any correlation between alcohol consumption and infertility, in contrast to most of the studies [22]. STI and varicocele are among the most common risk factors identified. Chlamydia trachomatis remains by far the most common pathogen [34]. Bah et al., however, found a history of gonorrhea in $17.9 \%$ [26]. Almost all studies reported either varicocele or varicocele surgery. It has been implicated in primary and secondary male infertility.

Although the present study is among the first multicenter report on epidemiology and risk factors of male infertility in the Sub-Saharan setting, some limitations should be noted. First, the lack of response from some patients led to the limitation of the sample size. Second, the fact that this study is not analytical reduces our ability to identify risk factors.

\section{Conclusion}

Male infertility accounts for $5.6 \%$ of all urological consultations in Douala, Cameroon. Intellectuals around 35 years old, married (probably reflecting the need of a child in the couple), with a higher level of education make up the bulk of the patients followed in urology for infertility. Factors associated with male infertility in our setting include alcohol consumption, STI, mumps history, herniorrhaphy, and varicocele presence. Further studies (analytics, with larger sample size) are thus needed for a detailed description in the Sub-Saharan setting.

\section{Abbreviations}

DGH: Douala General Hospital

SPSS: Statistical Package for Social Sciences

SSA: Sub-Saharan Africa

STI: Sexually transmitted infection

UMSCD: Urological Medico-surgical Centre of Douala

USA: United States of America

WHO: World Health Organization?

\section{Declarations}

\section{Ethics Approval and Consent to Participate}

The institutional review board of the Faculty of Medicine and Pharmaceutical Sciences of the University of Douala approved this work (registration number $\mathrm{N}^{\circ} 1688$ CEIUdo/02/2019/T). Administrative authorizations were obtained from the hospital administrations. We carried out this work in accordance with the declarations of Helsinki [35]. We report this work following the Standard for Reporting Observational Studies in Epidemiology (STROBE) checklist.

\section{Consent to Publish}

Not applicable

\section{Availability of Data and Materials}

The dataset analyzed during this study is not publicly available due to individual privacy issues. It could be available from the corresponding author on a reasonable request.

\section{Competing Interests}

The authors declare that they have no competing interests.

\section{Authors' Contribution}

Conception and Design: CTN, KD, EHMM, FGEN and SRSN. Data collection: KD. Administrative support: CTN, EHMM, FGEN. Data analysis and Interpretation: KD and FGEN

\section{Drafting of the Manuscript}

FGEN, SRSN, KD. Reviewing Manuscript: CTN, KD, EHMM, FGEN and SRSN. All the authors read and approved the final draft for publication.

\section{Acknowledgements}

We thank all the staff of DGH surgical and gynecological departments and all the staff of the Urological Medicosurgical Centre of Douala.

\section{References}

[1] Zegers-Hochschild F, Adamson GD, de Mouzon J, Ishihara O, Mansour R, Nygren K, et al. International Committee for Monitoring Assisted Reproductive Technology (ICMART) and the World Health Organization (WHO) revised glossary of ART terminology, 2009. Fertil Steril. 009; 92 (5): 1520-4.

[2] Jungwirth A, Diemer T, Kopa Z, Krausz C, Minhas S, Tournaye H. European Association of Urology guidelines on male infertility. Arnhem, The Netherlands: European Association of Urology; 2018 p. 1-47.

[3] Brzakowski M, Lourdel E, Cabry R, Oliéric M-F, Claeys C, Devaux A, et al. Épidémiologie du couple infertile. J Gynécologie Obstétrique Biol Reprod. 2009; 38: F3-7.

[4] Oakley L, Doyle P, Maconochie N. Lifetime prevalence of infertility and infertility treatment in the UK: results from a population-based survey of reproduction. Hum Reprod Oxf Engl. 2008; 23 (2): 447-50. 
[5] Zhou Z, Zheng D, Wu H, Li R, Xu S, Kang Y, et al. Epidemiology of infertility in China: a population-based study. BJOG Int J Obstet Gynaecol. 2018; 125 (4): 432-41.

[6] Chandra A, Copen CE, Stephen EH. Infertility and impaired fecundity in the United States, 1982-2010: data from the National Survey of Family Growth. Natl Health Stat Rep. 2013; (67): 1-18, $1 \mathrm{p}$ following 19.

[7] Agarwal A, Mulgund A, Hamada A, Chyatte MR. A unique view on male infertility around the globe. Reprod Biol Endocrinol. 2015; 13 (1): 37.

[8] Velu A, Prasad G. Epidemiologic aspects of male infertility. Int J Reprod Contracept Obstet Gynecol. 2017; 6 (8): 3362.

[9] Alam J, Choudhary P, Aslam M. Prospective study to evaluate the risk factors associated with male infertility at tertiary care centre. Int Surg J. 2018; 5 (8): 2862.

[10] Cong J, Li P, Zheng L, Tan J. Prevalence and Risk Factors of Infertility at a Rural Site of Northern China. Handelsman DJ, éditeur. PLOS ONE. 2016; 11 (5): e0155563.

[11] Sohrabvand F, Jafari M, Shariat M, Haghollahi F, Lotfi M. Frequency and epidemiologic aspects of male infertility. Acta Med Iran. 2015; 53 (4): 231-5.

[12] Aziz N, Agarwal A, Nallella KP, Thomas Jr AJ. Relationship between epidemiological features and aetiology of male infertility as diagnosed by a comprehensive infertility service provider. Reprod Biomed Online. 2006; 12 (2): 209-14.

[13] Olatunji AO, Sule-Odu AO. The pattern of infertility cases at a University Hospital. West Afr J Med. 1 janv 2003; 22 (3): 205-207.

[14] Gyasi-Sarpong C, Manu Maison P, Koranteng A. The pattern of male infertility in Kumasi, Ghana. Afr J Infertil Assist Concept. 2017; 2 (1): 3.

[15] Nana PN, Wandji JC, Fomulu JN, Mbu RE, Leke RJI, Woubinwou MJ. Aspects Psycho-Sociaux chez Patients Infertiles à la Maternite Principale de l'Hopital Central de Yaoundé, Cameroun. Clin Mother Child Health. 2011; 8: 1-5.

[16] Voundi Voundi E, Cyrille Noa Ndoua C, Belinga E, Ndoumba AM, Emmanuel Voundi Voundi J, Toukam M, et al. Factors Associated with Spermatic Abnormalities in Men Consulting for Couple Infertility at the Hospital Center for Research and Application in Endoscopic Surgery and Human Reproduction, Cameroon. Int Ann Med. 2018; 2 (11):. Disponible sur: https://iamresearcher.online/ojs/index.php/iam/article/view/66 1

[17] Benazzouz MH, Essatara Y, Sayegh HE, Iken A, Benslimane L, Nouini Y. Impact de la varicocèle sur le volume testiculaire et les paramètres spermatiques. Pan Afr Med J. 2014; 19: 1-8. Disponible sur: http://www.panafrican-medjournal.com/content/article/19/334/full/.

[18] Institut National de la Statitisque et des Etudes Economiques (INSEE). NOMENCLATURE DES PROFESSIONS ET CATEGORIES SOCIOPROFESSIONNELLES. Paris; $2016 \mathrm{p}$ 666. Report No.: 3è édition, 2003. Available at: https://www.insee.fr/fr/metadonnees/pcs2003/categorieSociop rofessionnelleAgregee/4? champRecherche=false.

[19] Diallo AB, Bah I, Barry M, Diallo TMO, Bah MD, Kanté D, et al. La varicocèle de l'adulte: aspects anatomo-cliniques et resultats therapeutiques au service d'urologie-andrologie du
CHU de Conakry, Guinee. Afr J Urol. 2015; 21 (2): 137-141.

[20] Moussa D, Soumana A, Amadou SM, Soli I, Tahirou I, Ali A. Profil hormonal chez l'homme en cas d'infertilité au laboratoire de radio immunologie de l'institut des radioisotopes de Niamey. Afr J Urol. 2016; 22 (4): 305-309309.

[21] Tijani KH, Oyende BO, Awosanya GO, Ojewola RW, Lawal AO, Yusuf AO. Scrotal abnormalities and infertility in west African men: A comparison of fertile and sub-fertile men using scrotal ultrasonography. Afr J Urol. 2014; 20 (4): 180-3.

[22] Okonofua F, Menakaya U, Onemu SO, Omo-Aghoja LO, Bergstrom S. A case-control study of risk factors for male infertility in Nigeria. Asian J Androl. 2005; 7 (4): 351-61.

[23] Uadia PO, Emokpae AM. Male infertility in Nigeria: A neglected reproductive health issue requiring attention. J Basic Clin Reprod Sci. 2015; 4 (2): 45-53-53.

[24] Martin-Odoom A, Brown CA, Adjei DN. Level of male infertility in the Ghanaian city of Tema. J Obstet Gynaecol J Inst Obstet Gynaecol. 2015; 35 (8): 825-8.

[25] Kirakoya B, Barnabé Z, Karim PA, Aristide KF, Clotaire Y, Amélie N. Epidemiological and Clinical Profile of Male Hypofertility in Consultation at the Urology-Andrology of Yalgado Ouedraogo Teaching Hospital (Burkina Faso). Adv Sex Med. 2014; 5 (1): 1-6.

[26] Bah OR, Diallo AB, Diallo A, Guirassy S, Bah I, Barry M, et al. Infertilité masculine: frdquence et aspects étiologiques au service d'Urologie-Andrologie du CHU de Conakry. Andrologie. 2007; 17 (3): 241-5.

[27] Sari-Minodier I, Loundou A, Ianos O, Ould Hamouda S, De Fleurian G, Lacroix-Paulmyer O, et al. Exposition professionnelle des hommes infertiles aux reprotoxiques: données du CHU de Marseille. Arch Mal Prof Environ. 2018; 79 (3): 300-1.

[28] Punab M, Poolamets O, Paju P, Vihljajev V, Pomm K, Ladva $\mathrm{R}$, et al. Causes of male infertility: a 9-year prospective monocentre study on 1737 patients with reduced total sperm counts. Hum Reprod. 17 2016; humrep; dew284v1.

[29] Niang L, Ndoye M, Labou I, Jalloh M, Kane R, Diaw JJ, et al. Profil épidémiologique et clinique de l'infertilité masculine à l'hôpital général de Grand-Yoff, Sénégal: à propos de 492 cas. Basic Clin Androl. 2009; 19 (2): 103-7.

[30] Traore M, Toure A, Sissoko S, Samake NF. Profil spermiologique des hommes infertiles au Mali. Andrologie. 2008; 18 (4): 253-7.

[31] Benbella A, Aboulmakarim S, Hardizi H, Zaidouni A, Bezad R. Infertility in the Moroccan population: an etiological study in the reproductive health centre in Rabat. Pan Afr Med J. 2018; 30: 204.

[32] Nwajiaku LA, Mbachu IL, Ikealo L. Prevalence, Clinical Pattern and Major Causes of Male Infertility in Nnewi, South East Nigeria: A Five-Year Review. AFRIMEDIC J. 2012; 3 (2): 16-9.

[33] Marinelli D, Gaspari L, Pedotti P, Taioli E. Mini-review of studies on the effect of smoking and drinking habits on semen parameters. Int J Hyg Environ Health. 2004; 207 (3): 185-92. 
[34] Zorn B. Le sperme «inflammatoire»: ses relations avec la fertilité. Andrologie. 2009; 19 (1): 35-44.

[35] Association Médicale Mondiale. Déclaration d'Helsinki de l'Association Médicale Mondiale: principes éthiques applicables aux recherches médicales sur des sujets humains. 2013. Disponible sur: https://www.wma.net/fr/policiespost/declaration-dhelsinki-de-lamm-principes-ethiquesapplicables-a-la-recherche-medicale-impliquant-des-etreshumains/. 